\title{
Measurement of Sound Level in Sport Natural Areas Using the Maintaining Athletes' Health Approach
}

\author{
${ }^{1}$ Mohammad Taheri Hossseinabadi, ${ }^{1}$ Seyed Mostafa Tayebi Sani*, ${ }^{2}$ Hooman Bahmanpour, \\ ${ }^{1}$ Ali Fahiminejad \\ ${ }^{1}$ Department of Physical Education, Faculty of Science, Shahrood Branch, Islamic Azad University, \\ Shahrood, Iran. ${ }^{2}$ Department of Environment, Faculty of Engineering, Shahrood Branch, Islamic Azad \\ University, Shahrood, Iran.
}

Submitted 03 August 2019; Accepted in final form 23 December 2019.

\begin{abstract}
Background. Numerous studies have been shown that exposure to recreational intense sounds increases the damages of the hearing system. Objectives. This research aims to measure the sound level in Darakeh mountainous region and the climbing routes. Methods. The stationary method was used to record the measurement points. The sound level on the routes was measured in the distance of one meter, in A level and as an equivalent level by a portable device and Decibel X software (Version 2019) and compared with the standard sound (OSHA-90 dBA). Sound pressure level parameters (SPL), average sound level ((LP) ), equivalent continuous sound level (Leq) and personal daily dose LAEp, d was also calculated. Results. The research findings indicate that the lowest and highest average sound level belongs to the station 9 (roadside) with $68.1 \mathrm{~dB}$ and station 6 (Kolbeh Koohsar restaurant) with $81.73 \mathrm{~dB}$, respectively. The results show the relatively high distance of sound level in most stations (except station 2) in comparison with the international standards. The average sound level in climbing routes, the equivalent level, and the personal daily dosage were 77.3, 87.69, and $86.44 \mathrm{~dB}$, respectively. Conclusion. Considering conditions of the region, the average time of athlete presence is one hour longer than the allowed time and they are exposed to high noise pollution which can be lead to physiological complications, aggression and temporary changes in the hearing threshold.
\end{abstract}

\section{KEYWORDS: Sound Pressure Level (SPL), World Health Organization (WHO), Outdoor Sports}

\section{INTRODUCTION}

Although sound waves are considered as an essential factor in human life, in some cases they are not pleasant. Exposure to excessive noise higher than the limits can cause annoyance and hearing loss in human (1). Noise pollution is defined as the propagation of sound and vibration higher than the allowed limits in open spaces (outdoors) and is one of the examples of environmental damages (2) and has obvious consequences on human health and ecosystems (3). Exposure to sound not only occurs in work environments but also includes non-occupational activities such as recreation times, transportation, shopping, etc. (4). Noise pollution has a significant role in dissatisfaction with area (5). Reducing outdoor sound pollution, if desirable for most users, determines acoustic comfort (6). In addition to harmful effects on the hearing system, noise as a general stressor can affect the cardiovascular system and causes nervous simulation, anxiety, mental and psychological problems (7). In some studies, sound effects as a

*. Corresponding Author:

Seyed Mostafa Tayebi Sani, Assistant Professor

E-mail: tayebi.sani@gmail.com 
stressor factor has been studied and noise pollution mentioned as a dangerous factor for human health (8). Based on Maschke, the stress caused by noise pollution has a psychological nature $(9,10)$ and exposure to sound, especially in thinking activities, affects the person's efficiency (11).

In general, it can be said that not only noisy environments causes disorders in communication and conversations, but also carelessness in brain activities and inconsistency of thinking activities. Furthermore, learning is reduced and the number of mistakes will be increased. Due to loud and sudden sounds which cause stress and fear, blood pressure, especially the pressure inside the skull increases, salivary secretions decreases and the mouth becomes dry (12). According to studies of World Health Organization and International Labor Organization, signs of physiological effects related to noise pollution in human are shown at the level of 30-60 dB, Also, severe physiological complications and diseases caused by that occur in higher levels and $85-120 \mathrm{~dB}(13$, 14). Exposure to higher levels can cause traceable effects or physiological measurements on the body which are called strain or tension. Here, in addition to the mental effects of changes in the nervous and brain waves, changes in blood pressure and heart rate, hardening of the vascular wall and changes in some hormones such as adrenaline and cortisol can be measured (15).

According to the World Health Organization (WHO) reports, exposure to sound pressure level of $80 \mathrm{~dB}$ can cause aggressive behaviors. Noise pollution in higher sound pressure levels (more than $85 \mathrm{~dB}$ ) causes direct effects on hearing organs, including Temporary Threshold Shift (TTS) and long term contacts cause Permanent Threshold Shift (PTS). According to medical surveys, signs of hearing power reduction were seen in those who have been exposed to a sound with the intensity of 80 $\mathrm{dB}(16,17)$. Disorders of the digestive system and increase in cholesterol and triglycerides and diabetes are the consequences of exposure to sound (18). Exposure to noise in the long term can cause hearing harms which individuals might not be aware of it (19-22), Fig 1 which is called sound effects pyramid shows the noise pollution consequences based on two parameters of severity and the number of people exposed to it.

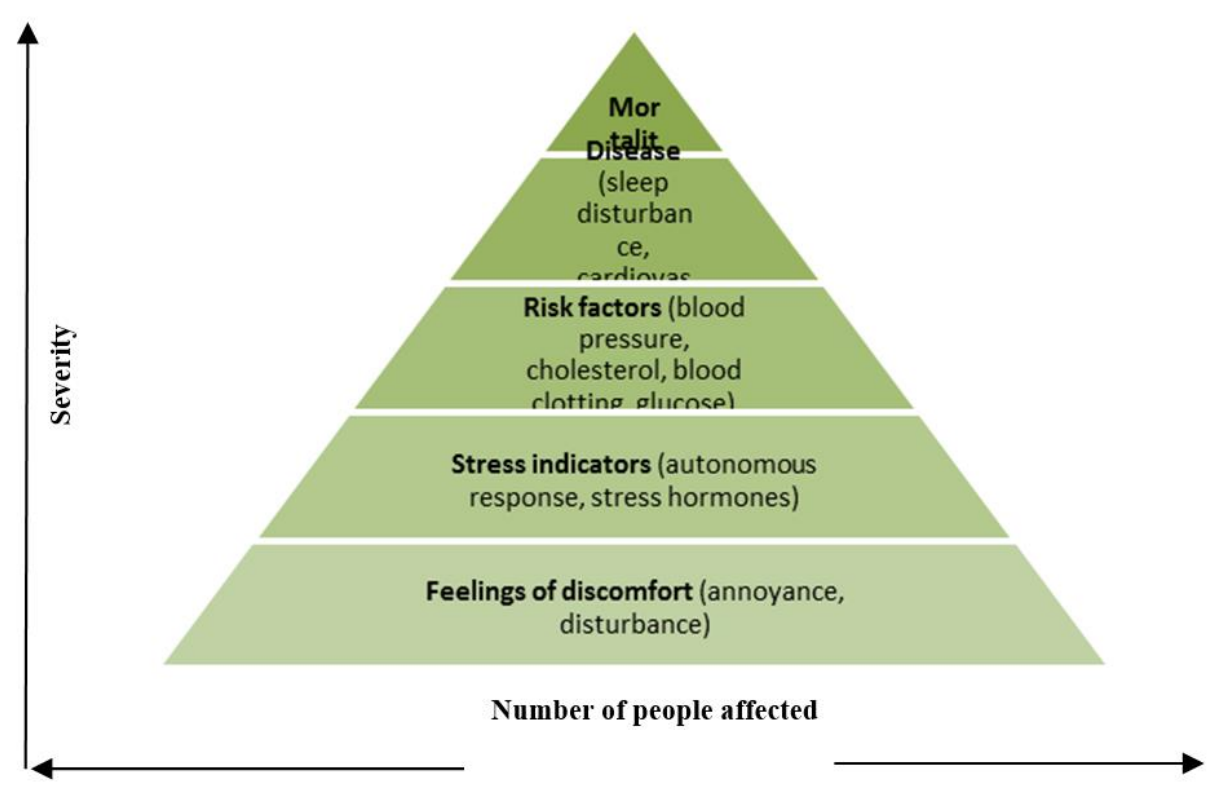

Figure 1. Sound effects pyramid (23)

In recent years, noise pollution and its consequences has become an important issue in scientific researches and numerous studies have been conducted to reduce the noise pollution problems in different cities and human settlements (24-26), It is more than two decades that water, soil and air pollution have been considered in Iran but still needs much efforts in noise pollution (27-29). While the increase of different urban activities has led to reveal the 
sound pollution as a social problem, but the importance of noise pollution in the country is not clear.

Noise pollution is monitored in three different fields: (1) Traffic and transportation, (2) Industrial activities, and (3) Sport, business and recreational areas. It has been clearly defined that noise pollution is a potential problem for health, communication and social life enjoyment (30). Numerous studies have been shown that exposure to recreational intense sounds increases the damages of hearing system $(31,32)$. New studies show that living in areas with high noise reduces the possibility of residents' exercising $(33,34)$. Noise also affects sleep quality which has a direct impact on one's tendency towards exercising. Lack of physical activity and exercising is one of the problems of modern society and researches are seeking for a way to overcome it. Reducing noise pollution in cities and terrific volume can be helpful in overcoming this problem. One of new approaches in sport management is sustainable sport management which benefits all the groups such as the public, athletes, and environmental activists. Sport can be universal, fruitful, and environmentally and socially sound (35). Sport activities can be called sustainable and healthy if guarantee psychological and physical health of the users (36). One of the environmental principals of Olympic Coordination Authority (OCA) is commitment to minimize the sound impacts on the environment and neighboring residential areas (33).

Literature Review. Based on the standards of Iranian Department of the Environment, the limits of equivalent sound pressure level for the residential area from 7 a.m. to 10 p.m. and is 10 p.m. to 7 a.m. is 55 and $45 \mathrm{~dB}$, respectively (37, 38) The standard of US Environment Protection Agency (EPA) for sound volume in open spaces (game grounds) is between 55 and $70 \mathrm{~dB}$. The standards of England for parks and recreational areas (A) are $55 \mathrm{~dB}$. According to some international standards and studies, sound pressure levels in sport areas should not be mort ham $55 \mathrm{~dB}$ and the sound higher than $85 \mathrm{~dB}$ has the ability to hurt the hearing system (39). The sound level for open and public spaces should not be more than $85 \mathrm{~dB}$ based on WHO (23).

This research aims to measure the sound level in Darakeh mountain recreational area which attracts many professional and armatures climbers, especially in the weekends. Considering number and variety of present users, it seems that the level of sound is higher in the area which will increase the probability of damages.

\section{MATERIALS AND METHODS}

The Study Area. Evin-Darakeh mountainous area is in the west north of Tehran and in longitude of $51^{\circ} 26^{\prime}$ and latitude of $35^{\circ} 48^{\prime}$ to $35^{\circ}$ 54'. As a part of central Alborz, the area is restricted from east to Aliabaad e Velenjak, Hesarak heights from west, Shahneshin and Tochal heights from north and Evin and Saadatabad from south. The study height varies between 1680-2200 metres (34). The narrow pathway of the mountains continues along the river to the highlands which is used as the main climbing routes (Fig 2).

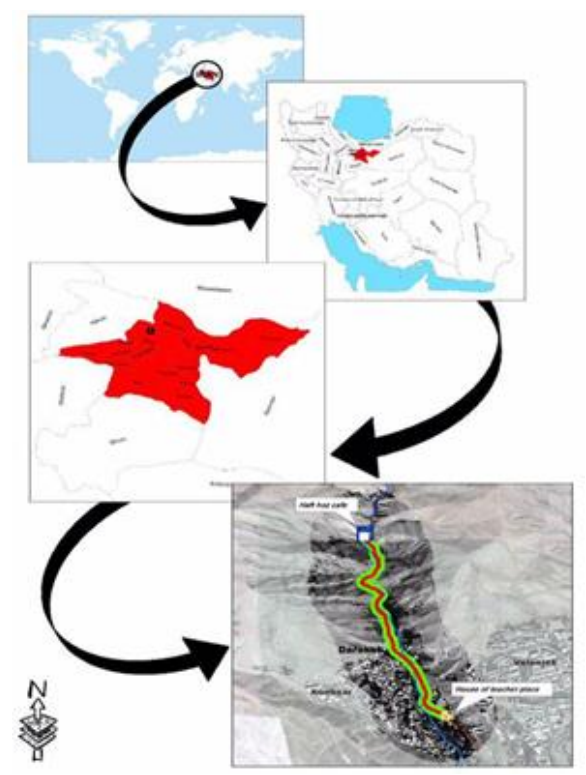

Figure 2. Location of Darakeh climbing routes

Procedure. This is a cross-sectional study and the data has been obtained by field research. Data analysis is analytical and comparative comparison carried out with the national and international standards. At first, the routes were determined by Geographic Position System (GPS). Next, points for map creation was entered into Geographical Information System (GIS) and the route map was created considering 30 meters band from every side, with the vast of $0.1 \mathrm{~km}^{2}$ (100 thousand square metres). For creation of sound level map in climbing routes, stationary method was used for recording the measurement points. hence, the athletes' climbing route (2182 metres) was divided into 11 stations from the end of Darakeh Street to Hafthoz Café (in 200 metres 
distance) (Fig 3). The characteristics of each measured stations are presented in table 1 .

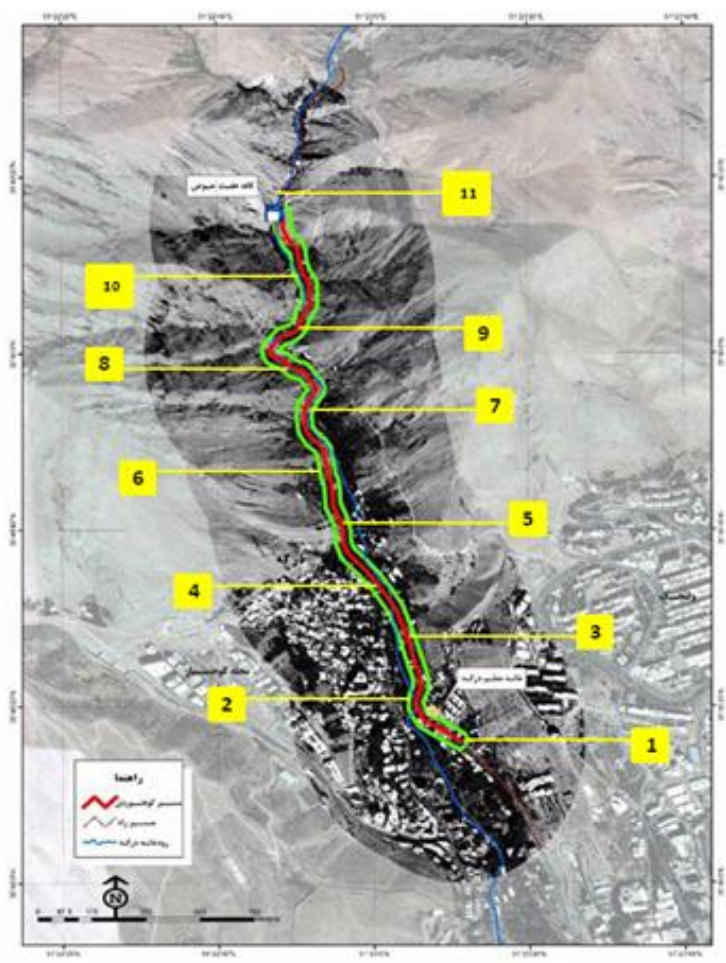

Figure 3. Position and the number of measurement stations of sound level in athletes' climbing route

The sound level on athletes' route in one metre distance, in A level and as an equivalent level was measured by a portable device and Decibel $\mathrm{X}$ software (Version 2019) and compared with the standard sound (OSHA-90 dBA). In evaluating the sound process, the sound level metre microphone was at least 3 metres away from reflective surfaces (such as walls) and 1.5 metres away from the ground (37). Also a distance equals to the length of an arm from the operator's body was considered. It should be noted that the error of up to $6 \mathrm{~dB}$ is negligible while evaluating (40). Measurement was carried out on days without precipitation and minimum wind. The measurement time at each station was 30 minutes (based on standards of Open Air by Iranian DOE), each was repeated three times. The first, second, and third measurement was carried out on 66:30 AM, 9-9:30 AM and 12-12:30 PM, respectively.

In the above relation, $\mathrm{P}$ is the absolute sound pressure in the measurement point and $P_{0}$ is the basic pressure which equals to $2 \times 10^{-5}$ Pascal (PA).

Table 1. The characteristics of eleven measurement stations of climbing route

\begin{tabular}{|c|c|c|}
\hline $\begin{array}{l}\text { Station } \\
\text { No }\end{array}$ & Station Name & $\begin{array}{l}\text { Station coordinates at } \\
\text { Longitude- Latitude }\end{array}$ \\
\hline 2 & $\begin{array}{l}\text { The beginning of the } \\
\text { climbing route- Mousavi } \\
\text { alley }\end{array}$ & $35,80745-51,38471$ \\
\hline 3 & $\begin{array}{l}\text { Saraye Mahalleh } \\
\text { Darakeh }\end{array}$ & $35,80990-51,38401$ \\
\hline 4 & Café Chenaran & $\begin{array}{c}35,8128810- \\
51,3822380\end{array}$ \\
\hline 5 & Baghe Gilas Restaurant & $\begin{array}{c}35,8150088- \\
51,3811664\end{array}$ \\
\hline 6 & $\begin{array}{l}\text { Kolbeh Koohsar } \\
\text { Restaurant }\end{array}$ & $\begin{array}{c}35,8151276- \\
51,3810996\end{array}$ \\
\hline 7 & $\begin{array}{l}\text { The margin of Darakeh } \\
\text { River }\end{array}$ & $\begin{array}{c}35,8159443- \\
51,3808955\end{array}$ \\
\hline 8 & Pakoopa Restaurant & $\begin{array}{c}35,8164435- \\
51,3799480\end{array}$ \\
\hline 9 & Roadside tation (1) & $\begin{array}{c}35,8197684- \\
51,3806510\end{array}$ \\
\hline 10 & Roadside station (2) & $\begin{array}{c}35,8202556- \\
51,3803057\end{array}$ \\
\hline 11 & $\begin{array}{l}\text { Hafthoz Café Restaurant } \\
\text { station }\end{array}$ & $\begin{array}{c}35,8207691- \\
51,3799349\end{array}$ \\
\hline
\end{tabular}

In this research, sound pressure level parameters (LP or SPL), average sound level $(\overline{\mathrm{LP}})$, equivalent continuous sound level (Leq) and personal daily dosage $\mathrm{L}_{\mathrm{AEp}, \mathrm{d}}$ were calculated. First, at each station the sound pressure level (dBA) was measured by a portable device based on the following relation and was recorded in the table (41).

$$
\begin{array}{r}
S P L(d B)=L P=10 \log \left(\frac{P^{2}}{P_{0}^{2}}\right) \\
=20 \log \left(\frac{P}{P_{0}}\right) \\
S P L=20 \log P+94
\end{array}
$$

Due to the logarithmic nature of the sound pressure levels, it is not possible to directly apply math operations such as addition, subtraction, or averaging. Therefore, the average sound level in the studied route is estimated from the following equation (35):

Relation (2)

$$
\overline{L P}(d B)=10 \log \left[\frac{1}{n}\right.
$$$$
\left.\times \sum_{i=1}^{n} 10^{\frac{L P i}{10}}\right]
$$

In this relation, $\mathrm{N}$ is the number of measurement points and LPi: sound pressure level on each point

Since the athlete is exposed to various levels of sound pressure during climbing, an equivalent 
level of sound exposure (dBA) Leq is used for accurate assessment. The following relation shows the calculation method (40):

$$
\begin{aligned}
& L_{e q}(d B) \\
& =10 \log \left[\frac{1}{T} \sum_{i=1}^{n} t_{i} 10^{L P_{i} / 10}\right]
\end{aligned}
$$

In this relation, $\mathrm{LP}_{\mathrm{i}}$ is the sound pressure level in time $t_{i}$ with equal units (in hours, minutes, or seconds) and $\mathrm{T}$ is the reference time.

Also; personal daily dosage of an athlete was calculated from the following relation (42):

$$
\text { Relation (4) LEp, } d=L e q+10 \log \frac{t}{m}
$$

In the above relation, Leq is the equivalent sound exposure level, $\mathrm{t}$ : the duration of athlete presence in the region, and $\mathrm{m}$ : the maximum time of exposure to noise pollution in according to International Labour Organization standards and is equal to 8 hours. According to the interview with the athletes, the average time spent on one day climbing in Darakeh Mountains is 6 hours. Using the standard published by the Health and Safety Executive on sound reductions in workplaces (South, 2016), the maximum exposure time limit was calculated for athletes in the mountains.

Various research centres have shown that the provision of noise pollution maps is one of the important tools for the study, detection and control of environmental pollution (43-45). To conduct an analysis in GIS, a digital map of the study area from the National Cartographic Centre of Iran (NCC) with a scale of 1: 10,000 in Shape file format was prepared and a GIS Ready map provided to create a spatial database and the relevant analyses. Then the sound data for unknown points was acquired via Spline method from Interpolation. In this case, the following equation was used to determine the level of sound pressure in the intervals between the stations:

$$
\begin{aligned}
& \text { Relation (5) } \quad L P_{2}=L P_{1}-20 \log r_{2} / r_{1} \\
& \mathrm{LP}_{1} \text { : pressure } \quad \mathrm{LP}_{2} \text { : } \quad \mathrm{r}_{1}, \quad \mathrm{r}_{2} \text { : } \\
& \text { level in distance pressure level distance from } \\
& \mathrm{r}_{1} \quad \text { in distance } \mathrm{r}_{2} \text { point source } \\
& \text { (m) }
\end{aligned}
$$

\section{RESULTS}

Sound pressure level (dBA) was measured and recorded in every station at different times. Also, the average sound level in each station and every time was calculated (Table 2). The lowest measured sound pressure level in the study area is in the station 10 and it has been $65.5 \mathrm{~dB}$ at the first time. Also, the highest measured sound level belongs to the station 4 and in the third time was $88.7 \mathrm{~dB}$. The measured sound pressure indicates that the average sound pressure level increases by time changing from early morning (6 AM) to noon (12 PM). In other words, there is a direct relation between the sound pressure level and increase in an athlete's presence in the area (Fig 4).

Table 2. The average 30-minutes sound pressure level in weighted network Leq ( $30 \mathrm{~min}) \mathrm{db}(\mathrm{A})$ in three times intervals in Darakeh climbing routes

\begin{tabular}{|l|ccccc|}
\hline $\begin{array}{l}\text { Station } \\
\text { No }\end{array}$ & First time 6-6:30 & Second Time 9-9:30 & Third time 12-12:30 & $\begin{array}{c}\text { The average sound } \\
\text { level in each station }\end{array}$ \\
\hline $\mathbf{1}$ & 69.3 & 73.4 & 84.8 & 75.83 \\
$\mathbf{2}$ & 69.8 & 70.5 & 76.7 & 72.33 \\
$\mathbf{3}$ & 67.3 & 68.6 & 73.7 & 69.86 \\
$\mathbf{4}$ & 70.5 & 84.8 & 88.7 & 81.33 \\
$\mathbf{5}$ & 70.5 & 78.2 & 81.3 & 76.66 \\
$\mathbf{6}$ & 77 & 83.8 & 84.4 & 81.73 \\
$\mathbf{7}$ & 77.1 & 77.4 & 84.1 & 79.53 \\
$\mathbf{8}$ & 70.5 & 76.4 & 78.8 & 75.23 \\
$\mathbf{9}$ & 66.3 & 66.8 & 71.2 & 68.1 \\
$\mathbf{1 0}$ & 65.5 & 68.5 & 78.2 & 70.73 \\
\hline $\mathbf{1 1}$ & 76.5 & 77.1 & 77.4 & 77.4 \\
\hline average & 70.93 & 75.04 & 70.93 & \\
\hline
\end{tabular}

In general, the lowest and highest average sound level belongs to the station 9 (side road) and station 6 (Kolbeh Koohsar restaurant) with $68.1 \mathrm{~dB}$ and $81.73 \mathrm{~dB}$, respectively. Fig 5 shows the relatively high distance of sound level in most stations (excluding two stations) comparing with
EPA standards for recreational areas and outdoors sport (Min: 55 and Max: $70 \mathrm{~dB}$ ). Also, there is a significant difference in comparison with sport and recreational and parks (England) which is 55 $\mathrm{dB}$. Since there is no standard for sound pressure level in outdoor spaces in Iran, there are no 
possibilities to compare it with national standards. However, regarding the permitted limitation in residential araes of DOE (7 AM- $10 \mathrm{PM}, 55 \mathrm{~dB}$; 10 PM-7 aM, $45 \mathrm{~dB}$ ), it can be found out that regarding the position of station 1,2 and 3 which are in residential and urban areas, sound level in this area is higher than the standars and causes annoyment and disturbance for the residents.

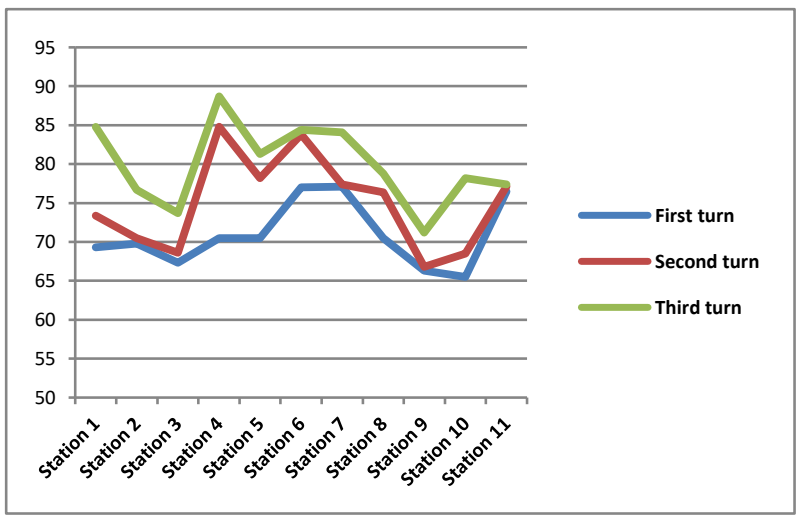

Figure 4. Calculated sound pressure level Leq (30 min) dB (A) in Darakeh climbing routes

Considering the diagrams (Fig 6) it can be concluded that the sound field is free type and since it has not been interrupted over time, it is continuous noise (sound) and fluctuating noise (sound) due to the fact that the pressure level changes is between 5 to15.

In the following and using relation (2), the average sound level along the climbing route was calculated which is equal to $77.3 \mathrm{~dB}$.

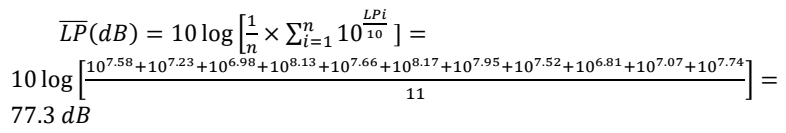

Then by the relation (3), the equivalent sound level Leq (dBA) was estimated. As said before, according to the interview with the athletes, the average time in one day climbing in Darakeh Mountain is 6 hours. Based on this, the equivalent level is estimated 87.69.

$$
L_{e q}(d B)=10 \log \left[\frac{1}{T} \sum_{i=1}^{n} t_{i} 10^{L P_{i} / 10}\right]=87.69(d B)
$$

In the following and using relation (4), personal daily dosage $L_{E p, d}$ of an athlete in the study area was calculated which is equivalent to 86.44

$$
\begin{gathered}
L_{E p, d}=L e q+10 \log \left(\frac{t}{m}\right) \\
L_{E p, d}=87.69+10 \log \left(\frac{6}{8}\right)=86.44(d B)
\end{gathered}
$$

It is obvious that an athlete is exposed to a high noise pollution in Darakeh. HSE nomogram was used for determining the permitted level of exposure to sound in the study area. Due to the equivalent level which is $87,69 \mathrm{~dB}$ and personal daily dosage $(86,44 \mathrm{~dB})$, we can calculate the duration of sound facing in Darakeh for athletes which is 5 hours (Fig 7).

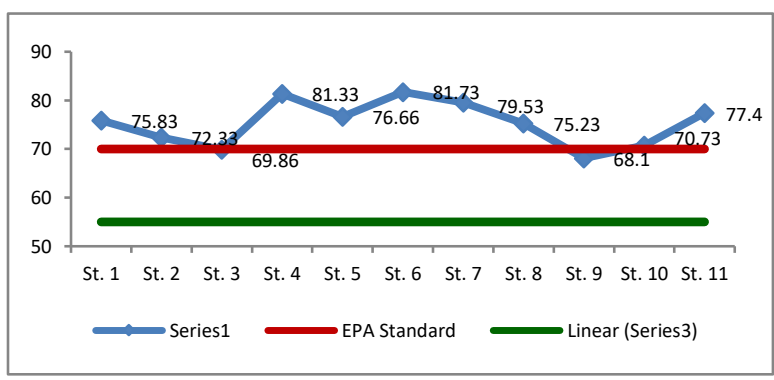

Figure 5. Comparative diagram of average sound level dB (A) measured in the station with international standards
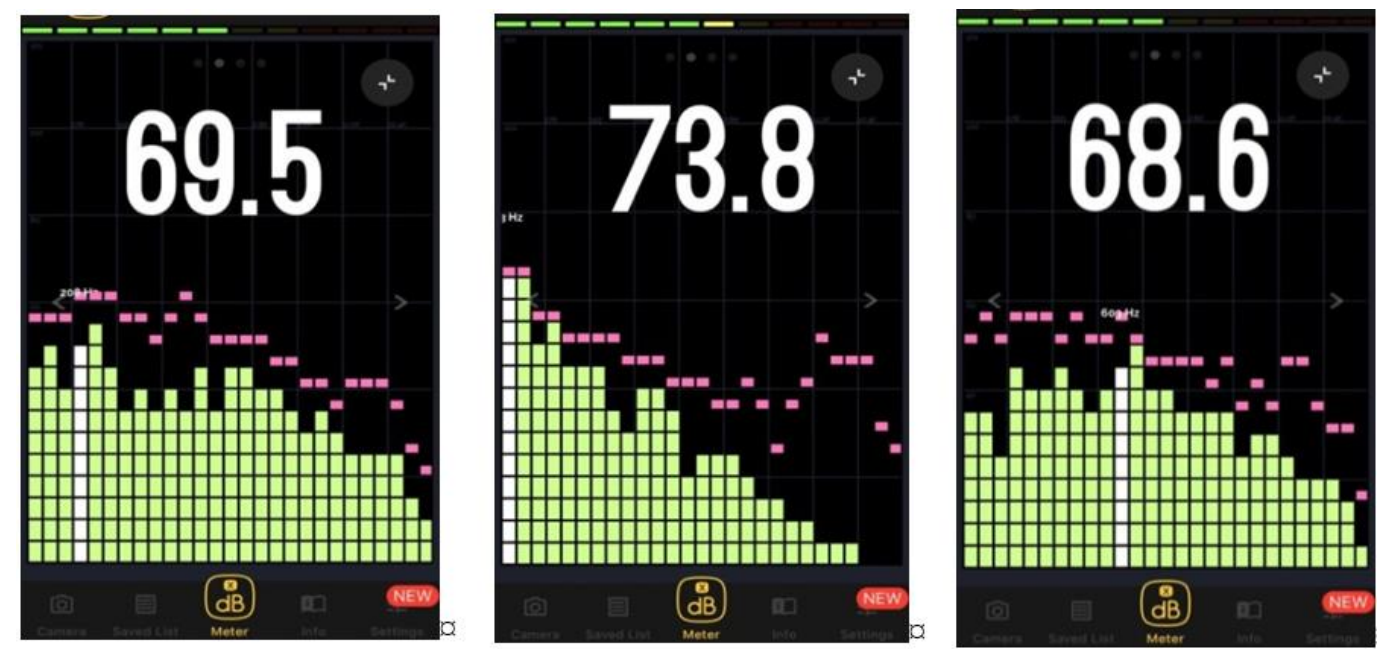

Figure 6. A few samples of sound level (dBA) SPL in the study areas 


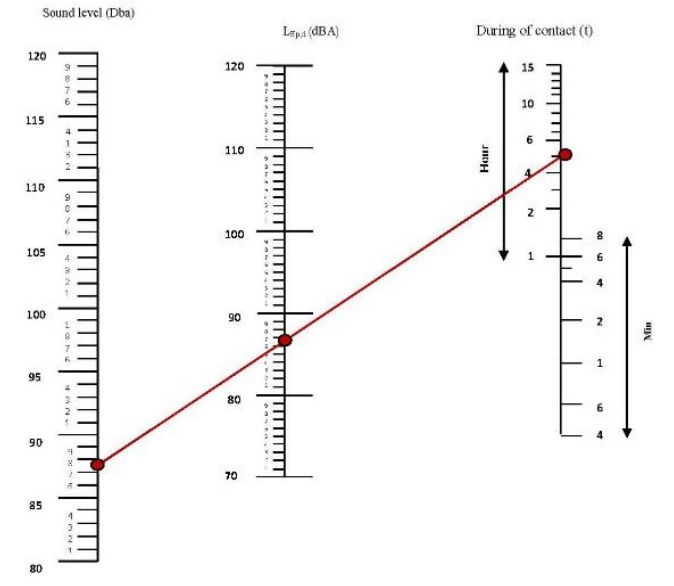

Figure 7. Nomogram of allowed duration of exposure to the sound for athletes in Darakeh

Using the sound level and data interpolation method, sound pollution map of the study area including Darakeh mountainous climbing route was created (Fig 8).

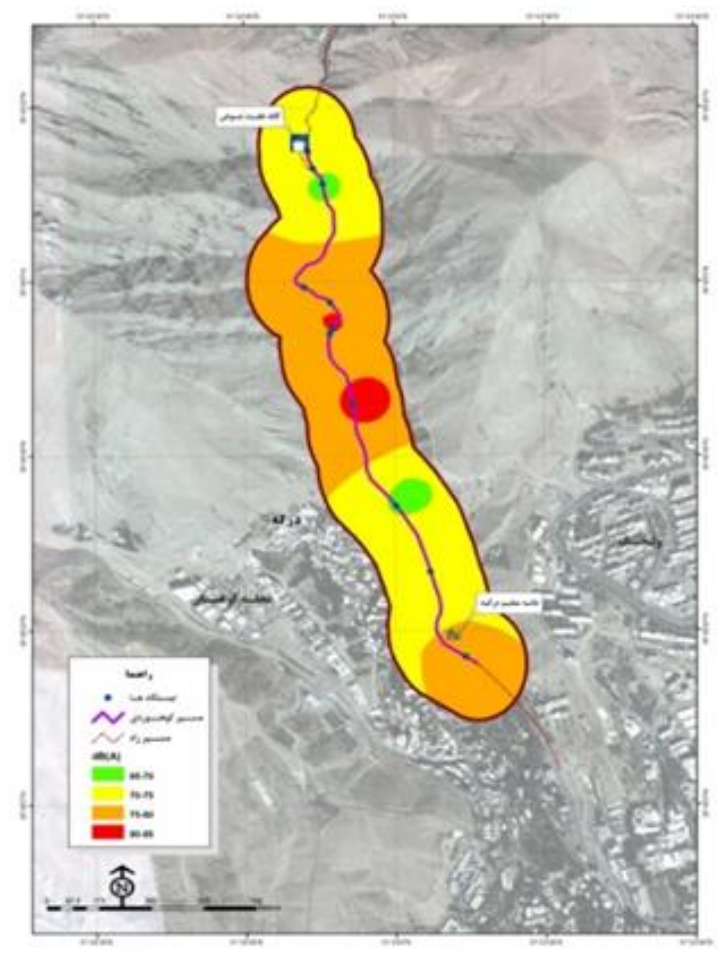

Figure 8. Noise pollution map in athletes' climbing route in Darakeh

\section{DISCUTION}

As shown in Fig 8, climbing route in Darakeh is divided into some categories based on the sound level. Although a big part of study region is located in yellow and orange zone, the green shows sound level of 65-70 dB and standard area. Yellow presents $70-75 \mathrm{~dB}$ and acceptable area. Orange shows 75-80 sound level and higher than standard and red displays 80-85 dB sound level and annoying and unsafe region. Darakeh region attracts a significant number of users for sport and tourism activities, especially on holidays and weekends. Most users (especially amateur ones) move in approximately 2182 metres. Concentration and movement of athletes and various uses such as cafes, restaurants, etc. leads to increase the sound level in the climbing route and surrounding areas. The survey results indicate that by changing the time from early morning (6 AM) to noon (12 PM), the sound level is increased (from 70, 93 to $79,93 \mathrm{~dB}$ ) due to the increase of number of users in the region. On the other hand, activities of services in the region will increase with the presence of athletes which also leads to an increase in sound level. The average sound level measured along the climbing route is $77,3 \mathrm{~dB}$ which is not compliant with EPA standard as well as the standards of UK and WHO and shows a higher level which definitely had the ability to hurt the athletes health. Therefore, it can be defined that considering the conditions of the region, the time of athletes' presence is about 1 hour longer than the permitted time.

\section{CONCLUSION}

Considering that the daily dosage of a person in the region is $86,44 \mathrm{~dB}$, and 6 hours presence of people in the region (on average), athletes are exposed to annoying sounds one hour longer than the standard, according to HSE guidelines. This means they need to decrease their presence hours to 5 hours (on average) to protect their health. Given the equal level 87, $69 \mathrm{~dB}$ in Darakeh which athletes are exposed, aggressive behaviours, physiological complications, as well as temporary changes in hearing thresholds can be expected, if it repeated in the long term. Also, the region's noise pollution map shows that the highest sound level can be seen between station 4 to 9 due to narrowing of the route and the population concentration as well as the number of services. Therefore, it has been suggested that athletes do not stop at these areas and pass it immediately. Also, the region's management is supposed to remind the restaurants to decrease their noise pollution. 


\section{APPLICABLE REMARKS}

Based on the results of the present study, it is suggested that managers and planners in the study area focus on several issues. The first is to remove sources of noise pollution in the study area and the second is to select alternative routes. It is also advisable to inform athletes and users through guides. Many athletes are unaware of the serious damage caused by noise pollution.

\section{REFERENCES}

1. Agrawal Y, Niparko JK, Dobie RA. Estimating the effect of occupational noise exposure on hearing thresholds: the importance of adjusting for confounding variables. Ear Hear. 2010;31(2):234-237. doi: 10.1097/AUD.0b013e3181c6b9fd pmid: 20075736

2. Vogiatzis K. Airport environmental noise mapping and land use management as an environmental protection action policy tool. The case of the Larnaka International Airport (Cyprus). Sci Total Environ. 2012;424:162-173. doi: 10.1016/j.scitotenv.2012.02.036 pmid: 22425171

3. WHO. Burden of disease from environmental noise quantification of healthy life years lost in Europe 2011. Copenhagen: World Health Organization Regional Office for Europe, 2011.

4. Clark C, Head J, Stansfeld SA. Longitudinal effects of aircraft noise exposure on children's health and cognition: A six-year follow-up of the UK RANCH cohort. J Environ Psychol. 2013;35:1-9. doi: 10.1016/j.jenvp.2013.03.002

5. Parkes A, Kearns A, Atkinson R. What Makes People Dissatisfied with their Neighbourhoods? Urban Stud. 2016;39(13):2413-2438. doi: 10.1080/0042098022000027031

6. Yang W, Kang J. Acoustic comfort evaluation in urban open public spaces. Appl Acoustics. 2005;66(2):211-229. doi: 10.1016/j.apacoust.2004.07.011

7. Bazaras J. Internal Noise Modelling Problems of Transport Power Equipment. Transport. 2006;21(1):19-24. doi: 10.3846/16484142.2006.9638035

8. Zannin PHT, Calixto A, Diniz FB, Ferreira JAC. A survey of urban noise annoyance in a large Brazilian city: the importance of a subjective analysis in conjunction with an objective analysis. Environ Impact Asses Rev. 2003;23(2):245-255. doi: 10.1016/s0195-9255(02)00092-6

9. Sommerhoff J, Recuero M, Suárez E. Community noise survey of the city of Valdivia, Chile. Appl Acoustics. 2004;65(7):643-656. doi: 10.1016/j.apacoust.2004.01.003

10. Babisch W, Pershagen G, Selander J, Houthuijs D, Breugelmans O, Cadum E, et al. Noise annoyance-a modifier of the association between noise level and cardiovascular health? Sci Total Environ. 2013;452-453:50-57. doi: 10.1016/j.scitotenv.2013.02.034 pmid: 23500398

11.Emmett SD, Francis HW. The socioeconomic impact of hearing loss in U.S. adults. Otol Neurotol. 2015;36(3):545-550. doi: 10.1097/MAO.0000000000000562 pmid: 25158616

12. Babisch W, Kamp I. Exposure-response relationship of the association between aircraft noise and the risk of hypertension. Noise Health. 2009;11(44):161-168. doi: 10.4103/1463-1741.53363 pmid: 19602770

13. Munzel T, Sorensen M, Schmidt F, Schmidt E, Steven S, Kroller-Schon S, et al. The Adverse Effects of Environmental Noise Exposure on Oxidative Stress and Cardiovascular Risk. Antioxid Redox Signal. 2018;28(9):873-908. doi: 10.1089/ars.2017.7118 pmid: 29350061

14. Hassmen P, Koivula N. Cardiac deceleration in elite golfers as modified by noise and anxiety during putting. Percept Mot Skills. 2001;92(3 Pt 2):947-957. doi: 10.2466/pms.2001.92.3c.947 pmid: 11565938

15.Hansell AL, Blangiardo M, Fortunato L, Floud S, de Hoogh K, Fecht D, et al. Aircraft noise and cardiovascular disease near Heathrow airport in London: small area study. BMJ. 2013;347:f5432. doi: 10.1136/bmj.f5432 pmid: 24103537

16. Stansfeld S, Haines M, Brown B. Noise and health in the urban environment. Rev Environ Health. 2000;15(1-2):43-82. pmid: 10939085

17.Stansfeld SA, Matheson MP. Noise pollution: non-auditory effects on health. Br Med Bull. 2003;68:243257. doi: 10.1093/bmb/ldg033 pmid: 14757721

18. Klatte M, Bergstrom K, Lachmann T. Does noise affect learning? A short review on noise effects on cognitive performance in children. Front Psychol. 2013;4:578. doi: 10.3389/fpsyg.2013.00578 pmid: 24009598 
19. Blanchfield BB, Feldman JJ, Dunbar J. The severely to profoundly hearing impaired population in the United States: prevalence and demographics. Policy Anal Brief H Ser. 1999;1(1):1-4. pmid: 11763876

20. Vogel I, Brug J, van der Ploeg CP, Raat H. Young people's exposure to loud music: a summary of the literature. Am J Prev Med. 2007;33(2):124-133. doi: 10.1016/j.amepre.2007.03.016 pmid: 17673100

21. Muhr P, Rasmussen F, Rosenhall U. Prevalence of hearing loss among 18-year-old Swedish men during the period 1971-1995. Scand J Public Health. 2007;35(5):524-532. doi: 10.1080/14034940701281477 pmid: 17852986

22. Sorensen M, Andersen ZJ, Nordsborg RB, Jensen SS, Lillelund KG, Beelen R, et al. Road traffic noise and incident myocardial infarction: a prospective cohort study. PLoS One. 2012;7(6):e39283. doi: 10.1371/journal.pone.0039283 pmid: 22745727

23.WHO. Burden of Disease from Environmental Noise. Quantification of Health Life Years Lost in Europe. Copenhagen, Denmark: World Health Organization and Joint Research Council, 2011.

24. Babisch W, Houthuijs D, Pershagen G, Cadum E, Katsouyanni K, Velonakis M, et al. Annoyance due to aircraft noise has increased over the years--results of the HYENA study. Environ Int. 2009;35(8):1169-1176. doi: 10.1016/j.envint.2009.07.012 pmid: 19699524

25. Abbaspoor M. Environmental engineering: Islamic Azad University publication; 2016.

26. WG-AEN. Good practice guide for strategic noise mapping and the production of associated data on noise exposure. European Commission Working Group Assessment of Exposure to Noise (WG-AEN), 2007.

27. Ghanbari M, Nadafi K, Mosaferi M, Yoonesian M, Aslani H. Study of noise pollution in the city of Tabriz in commercial and residential districts of Iran. J Health Environ Iranian Soc Environ Health. 2011;3:375-384.

28.Javaherian M, Abedi A, Esmaeili S, Khoeini F, Abedini Y, Asadi A, et al. Survey of Noise Pollution in Zanjan, and Comparing them with Standards. Int J Sci Eng Res. 2018;9(12):845-848. doi: 10.14299/ijser.2018.12.03

29. Barbaresco GQ, Reis AVP, Lopes GDR, Boaventura LP, Castro AF, Vilanova TCF, et al. Effects of environmental noise pollution on perceived stress and cortisol levels in street vendors. J Toxicol Environ Health A. 2019;82(5):331-337. doi: 10.1080/15287394.2019.1595239 pmid: 30915910

30. Sukru D, Celalettin O, Hakan K, Sain K. Noise pollution and map of Konja city in Turkey. J Int Environ Appl Sci. 2006;1(1-2):63-72.

31.Clark WW. Noise exposure from leisure activities: a review. J Acoust Soc Am. 1991;90(1):175-181. doi: 10.1121/1.401285 pmid: 1880286

32. Dalton DS, Cruickshanks KJ, Wiley TL, Klein BEK, Klein R, Tweed TS. Association of Leisure-Time Noise Exposure and Hearing Loss:Asociación entre exposición a ruido durante el tiempo libre e hipoacusia. Int J Audiol. 2001;40(1):1-9. doi: 10.3109/00206090109073095

33. Tin LL, Lim OP. A study on the effects of discotheque noise on the hearing of young patrons. Asia Pac J Public Health. 2000;12(1):37-40. doi: 10.1177/101053950001200108 pmid: 11200216

34. Bahmanpour H, Salajegheh B, Mafi A. Investigating the Environmental Situation of Darband Mountains, Environmental Report. Environmental and Energy Research Center, 2011.

35.IOC. Agenda21 for Sport. Lausanne: International Olympic Committee; nternational Olympic Committee.

36. Chernushenko D, van der Kamp A, Stubbs D. Sustainable sport management: Running an environmentally, socially and economically responsible organization: UNEP; 2001.

37. OEL. Assessment guideline for Noise and Vibration. Iran Islamic Republic of Iran Ministry of Health and Medical Education, Environmental and Occupational Health Center, 2017.

38. Monazzam MR, Karimi E, Abbaspour M, Nassiri P, Taghavi L. Spatial traffic noise pollution assessment - A case study. Int J Occup Med Environ Health. 2015;28(3):625-634. doi: 10.13075/ijomeh.1896.00103 pmid: 26190737

39.Dursun Ş, Özdemir C. Preparing the Map of Noise Pollution in Konya City Centre. Konya: 1999.

40. Ringen K. National Conference on Ergonomics, Safety, and Health in Construction summary report. Am J Ind Med. 1994;25(6):775-781. doi: 10.1002/ajim.4700250602 pmid: 8067355

41.Geravandi S, Takdastan A, Zallaghi E, Vousoghi Niri M, Mohammadi MJ, saki H, et al. Noise Pollution and Health Effects. Jundishapur J Health Sci. 2015;7(1). doi: 10.5812/jjhs.25357 
42. South T. Managing noise and vibration at work. Oxford: Elsevier; 2004.

43. Golmohammadi R, Monazzam MR, Nourollahi M, Nezafat A, Momen Bellah Fard S. Evaluation of noise propagation characteristics of compressors in tehran oil refinery center and presenting control methods. J Res Health Sci. 2010;10(1):22-30. pmid: 22911913

44. South T. Managing noise and vibration at work; a practical guide to assessment, measurement and control: Routledge; 2016.

45. Nassiri P, Monazam Esmaeelpour M, Rahimi Foroushani A, Ebrahimi H, Salimi Y. Occupational noise exposure evaluation in drivers of bus transportation of Tehran City. Iran J Health Environ. 2009;2(2):124-131. 